\title{
Papers
}

\section{Randomised controlled trial of animal facilitated therapy with dolphins in the treatment of depression}

Christian Antonioli, Michael A Reveley

\begin{abstract}
Objective To evaluate the effectiveness of animal facilitated therapy with dolphins, controlling for the influence of the natural setting, in the treatment of mild to moderate depression and in the context of the biophilia hypothesis.

Setting The study was carried out in Honduras, and recruitment took place in the United States and Honduras. Design Single blind, randomised, controlled trial.

Participants Outpatients, recruited through announcements on the internet, radio, newspapers, and hospitals.

Results Of the 30 patients randomly assigned to the two groups of treatment, two dropped out of the treatment group after the first week and three withdrew their consent in the control group after they had been randomly allocated. For the participants who completed the study, the mean severity of the depressive symptoms was more reduced in the treatment group than in the control group (Hamilton rating scale for depression, $\mathrm{P}=0.002$; Beck depression inventory, $\mathrm{P}=0.006$ ). For the sample analysed by modified intention to treat and last observation carried forward, the mean differences for the Hamilton and Beck scores between the two groups was highly significant ( $\mathrm{P}=0.007$ and $\mathrm{P}=0.012$, respectively).

Conclusions The therapy was effective in alleviating symptoms of depression after two weeks of treatment. Animal facilitated therapy with dolphins is an effective treatment for mild to moderate depression, which is based on a holistic approach, through interaction with animals in nature.
\end{abstract}

\section{Introduction}

Although public demand for alternative treatments in psychiatry-particularly animal facilitated therapy-has increased considerably in recent years, the lack of adequately controlled and designed research studies has led to considerable speculation. We studied the effectiveness of animal facilitated therapy with dolphins in treating mild to moderate depression and in the context of the biophilia hypothesis, controlling for the influence of the natural setting.

The term biophilia was first used by psychologist Erich Fromm to underline "the need for cultivating the capacity for love as a basis for our mental health and emotional wellbeing."1-3 Kellert and Wilson further developed the concept of biophilia. ${ }^{12}$ Its expression shows how human health and wellbeing are strictly dependent on our relationships with the natural environment. In the biophilic vision, the manifestation of emotions and the affiliation with the living diversity are an innate human tendency. Disrupting the affiliation with nature and thus losing the biophilic equilibrium means altering and damaging our psychophysical health. ${ }^{45}$

Rates of depression seem to be higher in industrialised countries than in developing ones. ${ }^{6}{ }^{7}$ Numerous researchers have presented evidence showing the therapeutic value of nature and animals for sick and disabled people. ${ }^{8-12}$ The aetiology of affective disorders includes genetic, biochemical, psychological, sociological, and environmental factors. ${ }^{53-16}$ Among the several aspects of biophilia, we focused our study on the therapeutic benefit that the interaction with animals may have in treating mild to moderate depressive disorders. This aspect is an integral part of the concept of biophilia. We chose the bottlenose dolphin, Tursiops truncatus, was the species chosen for the animal facilitated therapy and mild to moderate depression (according to the diagnostic criteria for research from ICD-10-International Classification Of Diseases, 10th revision ${ }^{17}$ ) as the illness to be treated. We examined biopsychological changes derived from the therapeutic use of dolphins and the effectiveness of this treatment, controlling for the influence of the natural setting (for example, water) and other non-specific environmental factors.

\section{Methods}

We studied outpatients, recruited through announcements on the internet, radio, newspapers, and hospitals in the United States and Honduras between November 2002 and December 2003, who had a diagnosis of a mild or moderate depressive disorder according to ICD-10 criteria. ${ }^{17}$ To avoid social desirability bias in responses to assessment, we emphasised the fact that people were only taking part in a research study and told them not to expect any improvement. Eligibility criteria for the study included an age of 18-65 and a score of at least 11 on the modified, 17 item, Hamilton rating scale for depression ${ }^{18}$ at baseline, after a period of four weeks without taking drugs. On this scale, higher scores indicate more severe depression. Serious anxiety disorder was defined a priori as a score on Zung's self rating anxiety scale of 45 or more. ${ }^{19}$ Patients were required to discontinue taking any kind of antidepressant drugs or psychotherapy at least four weeks before entering the study. We excluded patients with psychotic features, major depressive disorders, cyclothymia, or bipolar disorders. Patients were not allowed to take antidepressant or anxiolytic drugs during the study.

\section{Procedure}

All patients provided written informed consent to participate. Field research work took place at the Roatan Institute for Marine Sciences (Roatan, Bay Islands, Honduras) between July 2002 and December 2003. After participants had read the information 
form we asked them for a medical certificate from their treating therapist that confirmed a diagnosis of mild or moderate depression without psychotic features. Once participants had been selected by the panel of psychiatrists and clinical psychologists, and on their arrival at the institute, they were asked to sign the patients' consent form. A psychological and medical examination was then done, and participants received an induction to the institute facilities and the island. Experienced clinical raters who were blinded to treatment assignments, to the hypothesis under testing, and to the fact that block randomisation was being used administered the Hamilton rating scale for depression at baseline and at the end of the treatment.

We followed this protocol during the entire research period. We used block randomisation to assign participants randomly to one of two groups of treatment. ${ }^{20} \mathrm{~A}$ research assistant used a random number table to generate the block allocation sequence. The block lengths were 2, 4, 6 and varied randomly. The allocation sequence was concealed until treatments were assigned. We kept the randomisation sequence hidden from the investigators giving the treatments by using a set of opaque numbered sealed envelopes, each containing the allocation for one patient. The appropriate envelope then went to an external medical officer. In the experimental group, all subjects were assigned to an animal care programme, and all trials were conducted in the presence of dolphins. Participants were asked to play, swim, and take care of the animals. They had an introductory session, to explain about dolphin behaviour and water safety. The first part of the trial, which took half an hour, was structured so the participants could familiarise themselves with the animals. Participants were standing in the water, close to the trainer. The dolphins, following the trainer's signals, performed trained behaviours (such as a jump or a swim). Participants were able to touch the dolphins when close to the trainer. The second part of the trial, another half an hour, was unstructured, and free and spontaneous interactions occurred. Participants were snorkelling in the water with the dolphins. In the control group, participants were assigned to an outdoor nature programme featuring the same water activities as the animal care programme but in the absence of dolphins, to control for the influence of water and other, non-specific, environmental factors. In the outdoor nature programme, participants had to swim and snorkel in the barrier coral reef for one hour a day and had a similar degree of individualised human contact as in the animal care programme. Patients were informed of the marine ecosystem, the barrier coral reef (the second largest in the world after the great barrier reef of Australia), and water safety.

Each session took about one hour a day. To avoid disappointment for the participants in the control group, which might have affected the results of the study, they also had a day session with the dolphins at the end of the treatment and after the final evaluation. Both programmes were run simultaneously and lasted for a period of two weeks for each group. The treatments were given daily, Monday to Friday, one hour per day.

\section{Assessment}

Behavioural and psychological measures were conducted at baseline and at the end of treatment by using a modified, 17 item, Hamilton rating scale for depression, ${ }^{18}$ the Beck depression inventory, ${ }^{21}{ }^{22}$, and the Zung self rating anxiety scale. ${ }^{19}$ In the modified Hamilton scale, we did not consider the last four original items because they describe aspects of the illness rather than its severity (such as diurnal variation). We defined a clinically important improvement a priori as a Hamilton score of no more than 7 at the end of treatment, and a satisfactory therapeutic
Table 1 Baseline characteristics of the randomised patients. Values are numbers (percentages) of patients unless otherwise indicated

\begin{tabular}{lccc} 
Characteristic & $\begin{array}{c}\text { Animal care } \\
\text { programme } \\
(\mathbf{n}=\mathbf{1 5})\end{array}$ & $\begin{array}{c}\text { Outdoor nature } \\
\text { programme } \\
(\mathbf{n}=\mathbf{1 5})\end{array}$ & $\begin{array}{c}\text { All participants } \\
(\mathbf{n}=\mathbf{3 0})\end{array}$ \\
\hline Female sex & $14(93)$ & $13(87)$ & $27(90)$ \\
\hline White & $12(80)$ & $10(67)$ & $22(73)$ \\
\hline Mean age in years (SD) & $41.0(12.5)$ & $39.5(10.8)$ & $40.2(11.5)$ \\
\hline
\end{tabular}

\begin{tabular}{lllr}
\hline Marital status: & $3(20)$ & $4(27)$ & $7(23)$ \\
\hline Married or cohabiting & $8(53)$ & $8(53)$ & $16(53)$ \\
\hline Single & $4(26)$ & $3(20)$ & $7(23)$ \\
\hline Divorced or separated & & & \\
\hline Depression diagnosis: & $6(40)$ & $7(47)$ & $13(43)$ \\
\hline Mild depression & $9(60)$ & $8(53)$ & $17(57)$ \\
\hline Moderate depression & $5(33)$ & $7(47)$ & $12(40)$ \\
\hline Anxiety symptoms & & & \\
\hline Prior treatment for depression: & $6(40)$ & $5(33)$ & $11(37)$ \\
\hline None & $2(13)$ & $2(13)$ & $4(13)$ \\
\hline Psychotherapy & $4(26)$ & $6(40)$ & $10(33)$ \\
\hline Antidepressants & $3(20)$ & $2(13)$ & $5(17)$ \\
\hline Antidepressants and psychotherapy &
\end{tabular}

The difference between the groups did not reach significance.

response as a reduction in the Hamilton score by at least $50 \%$ from baseline to the end of treatment.

Our hypothesis was that a clinically important improvement of the depressive symptoms of the patients would be $80 \%$ in the animal care programme and $30 \%$ in the control group. On the basis of 0.8 power to detect a significant difference $(\mathrm{P}=0.05$; two sided), we needed 30 patients in total. To compensate for patients whom we could not evaluate, we planned to enrol 50 patients in total.

\section{Statistical analysis}

We used SPSS, version 11 (SPSS, Chicago, IL, USA) for our statistical analysis. We conducted preliminary $t$ tests for equality of means for two independent groups of observations for the Hamilton, Beck, and Zung's scores, to evaluate the significance of the changes in the scores from baseline to the end of treatment. The primary analysis was a modified analysis by intention to treat and last observation carried forward.

\section{Results}

Altogether 105 patients responded to the invitations for the study. We included 50 patients but then excluded 20 of these for non-compliance or other reasons (for example, they could not reach the island); 55 patients did not meet the selection criteria. A total of 30 patients underwent block randomisation: 15 were assigned to the experimental group to take part in the animal care programme, and 15 to the control group, to take part in the outdoor nature programme (table 1). In the control group, three participants withdrew their consent before the treatment started, and in the experimental group, two participants dropped out after the first week of treatment.

\section{Treatment and efficacy}

The preliminary two tailed $t$ test for equality of means for two independent groups of observations for the Hamilton and Beck scores from baseline to the end of treatment was highly significant in the patients who completed treatment (animal care programme, $n=13$; outdoor nature programme, $n=12$ ). For the Hamilton scale $(95 \%$ confidence interval $1.66 \%$ to $6.11 \%$, $\mathrm{P}=0.002$; equal variances not assumed), the mean differences in change scores for the animal care programme and the outdoor nature programme were 8.38 (SD 1.98) and 4.50 (SD 3.15), 
respectively. For the Beck depression inventory-IA $(2.43 \%$ to $13.3 \%, \mathrm{P}=0.006$; equal variances assumed), the mean differences in scores between the programmes were 15.46 (SD 5.69) and 7.58 (SD 7.42), respectively. Therefore the animal care programme had a significantly higher effect in decreasing the depressive symptoms of the subjects than the outdoor nature programme.

For the modified analysis by intention to treat and last observation carried forward, the two tailed $t$ test for equality of means for two independent groups of observations confirmed the significant differences for the Hamilton and Beck scores (table 2). The animal care programme group improved significantly more than the outdoor nature programme group for both scales.

The proportion who fell below the cut-off point on the Hamilton scale (participants who completed the study and received a score no higher than 7 on this scale) was $77 \%$ for the animal care programme and $25 \%$ for the outdoor nature programme. For the sample analysed by modified intention to treat and last observation carried forward, the proportions were $67 \%$ and $20 \%$, respectively.

Although the mean anxiety scores in both treatment groups fell, the $t$ test for the Zung scores did not reach significance $(95 \%$ confidence interval $-0.65 \%$ to $9.24 \%, \mathrm{P}=0.086$; equal variance assumed). The mean difference in change scores for the animal care programme was 11.46 (SD 6.32) and for the outdoor nature programme 7.17 (SD 5.57). The animal care programme did not have a significantly greater effect in reducing the anxiety symptoms of the subjects than the outdoor nature programme. However, only $40 \%$ of the sample had a clinically important anxiety score before the treatment (Zung score $>45$ ). In other words, only $40 \%$ of the sample under study had mild or moderate depression with anxiety symptoms before the treatment. For the modified analysis by intention to treat and last observation carried forward, the $t$ test for equality of means for two independent groups of observations for the Zung scores did not reach significance (table 2).

\section{Discussion}

Animal facilitated therapy with dolphins is more effective than "water" therapy in treating people with mild to moderate depression after the influence of the natural setting has been controlled for, as shown by our randomised, single blind, controlled trial. The animal care programme improved the depressive symptoms of the participants significantly more than the outdoor nature programme. The natural setting itself is also an important factor that has to be considered in the treatment of emotional disorders. This is confirmed by other studies. ${ }^{82}{ }^{24}$ The effects exerted by the animals were significantly greater than those of just the natural setting. The echolocation system, the aesthetic value, and the emotions raised by the interaction with dolphins may explain the mammals' healing properties. Further research to explore the influence of sounds and the echolocation system is needed.

Depressive symptoms improved after two weeks of treatment. In conventional therapy-psychotherapy or drug therapysymptoms usually improve substantially after four weeks. No side effects were noted, although accidental injuries may occur. Although water phobia and inability to swim represent limitations of the treatment, the presence of dolphins may help to overcome such limitations, functioning as a distractive element. The difference in reduction of anxiety symptoms between the animal care programme and the outdoor nature programme did not reach significance; however, only $40 \%$ of the sample under study had clinically important anxiety symptoms before the treatment. The overall reduction in the anxiety symptoms in both treatment groups may be explained by the therapeutic property of water in relieving anxiety, as shown in other studies. ${ }^{24}$

\section{Limitations}

A limitation of our study that is common to all studies of psychotherapy was our inability to blind participants to the treatment; knowledge of the intervention may therefore have influenced their reactions. Another limitation was posed by the restrictive exclusion criteria, which may reduce the generalisability of the findings. To avoid social desirability bias in responses to assessment, we emphasised to the patients the fact that they were only taking part in a research study and told them not to expect any improvement. To prevent disappointment in the participants in the control group-which might have affected the results of the study-they also had a day session with the dolphins after the final evaluation. Participants in the control group were therefore not excluded from an encounter with dolphins. Because of logistical and financial limitations, we did not do a follow-up study; however, three months or more after the intervention, the 10 participants in the animal care programme and the three participants in the outdoor nature programme who had a score of no more than 7 on the Hamilton rating scale for depression at the end of treatment (clinically important improvement) provided a self report about their mental health status. Nine of the 10 participants in the animal care programme and all three of the outdoor nature programme reported lasting improvement and did not require treatment.

Table 2 Mean of the difference in scores from baseline to end of study and mean scores at baseline and week 2 on the Hamilton rating scale for depression, Beck depression inventory, and Zung's self rating anxiety scale in the modified intention to treat sample*

\begin{tabular}{|c|c|c|c|c|c|c|}
\hline Variable & $P$ value $(95 \% \mathrm{Cl}) \dagger$ & $\begin{array}{c}\text { No of } \\
\text { participants }\end{array}$ & $\begin{array}{l}\text { Mean difference in change } \\
\text { scores (SD) }\end{array}$ & 95\% Clf & $\begin{array}{c}\text { Mean score at baseline } \\
\text { (SD) }\end{array}$ & $\begin{array}{c}\text { Mean score at week } 2 \\
\text { (SD) }\end{array}$ \\
\hline \multicolumn{7}{|c|}{ Hamilton rating scale for depression } \\
\hline Treatment group & 0.007 (1.112 to 6.221$)$ & 15 & $7.27(3.47)$ & 5.46 to 9.07 & $14.53(2.59)$ & $7.27(2.52)$ \\
\hline Control group & & 15 & $3.60(3.36)$ & 1.79 to 5.41 & $14.47(2.20)$ & $10.87(3.38)$ \\
\hline \multicolumn{7}{|c|}{ Beck depression inventory } \\
\hline Treatment group & 0.012 (1.774 to 12.89$)$ & 15 & $13.40(7.58)$ & 9.47 to 17.33 & $20.27(6.65)$ & $6.87(5.60)$ \\
\hline Control group & & 15 & $6.07(7.28)$ & 2.14 to 10.00 & $18.80(6.91)$ & $12.73(7.64)$ \\
\hline \multicolumn{7}{|c|}{$\underline{\text { Zung self rating anxiety scale }}$} \\
\hline Treatment group & 0.102 (NS) (0.861 to 8.994$)$ & 15 & $9.80(7.32)$ & 6.32 to 13.28 & $42.87(8.37)$ & $33.07(6.01)$ \\
\hline Control group & & 15 & $5.73(5.76)$ & 2.25 to 9.22 & $43.20(7.62)$ & $37.47(9.18)$ \\
\hline
\end{tabular}

* Scores represent the amount of reduction from baseline to end of treatment. Higher scores on the scales, indicate more severe depression or anxiety.

$t t$ test for independent groups of observations, comparing mean difference in change scores for treatment group and control group. The $95 \%$ confidence interval refers to the mean difference in $\dagger t$ test for independent groups of observat

$\ddagger$ Confidence interval for mean difference in change scores between baseline and week 2 . 


\section{What is already known on this topic}

Animal facilitated therapy may help improve psychological disorders

\section{What this study adds}

The biophilic method of intervention, which is based on a holistic approach through the interaction with animals in nature, and the stimulation of the nervous system through the senses, has the potential to bring alternative clinical strategies to the treatment of emotional disorders

Participants in both groups of the study (the animal care group and the outdoor nature group) reported lasting improvement of their symptoms

In patients with mild or moderate depression, using drugs or conventional psychotherapy may not be necessary when biophilic treatment with animals is used

\section{Conclusions}

The biophilic method of intervention represents a new emphasis in psychiatry and has the potential to bring alternative clinical strategies to the treatment of emotional disorders. Psychiatric rehabilitation occurs operating on the emotional, holistic, and psychophysical aspects of participants through the interaction with animals in nature and the stimulation of the nervous system through the senses. Our psychophysical health is strictly dependent on the environment, hence the importance to protect and conserve it.

We are thankful for the support given by the Tursiops Society Onlus and the advice and support given by Andrew Weil and Brian Becker of the University of Arizona, USA; Stephen Kellert of Yale University, USA; and Costantino Balestra of the Universitè Libre de Bruxelles, Belgium.We thank Yvonne Hartgers, Arnoldo Javier Montoya Stone, Aida Lagos, Hector Murcia Pinto for medical, psychological diagnosis and assistance; the research participants, the Psychiatric Hospital of Tegucigalpa and Roatan Hospital. We also thank the following for logistical support: Honduras Institute of Tourism; Universidad Nacional Autonoma de Honduras; Regione Piemonte, Italy; Anthony's Key Resort; IGV Club; TGI Diving; International Dolphin Watch; Voice Magazine Bay Islands; G Antonioli Clothing, Turin, Italy.

Contributors: CA participated in the design of the study, carried out the trial, and wrote the paper. MR led the design of the study, supervised the data analysis, and cowrote the paper. Both authors are joint guarantors.
Funding: Voluntary contributions acknowledged above.

Competing interests: None declared.

Ethical approval: Bioethical committee of the scientific research unit of the Universidad Nacional Autonoma de Honduras, Faculty of Medical Sciences.

1 Kellert SR. Kinship to mastery. Biophilia in human evolution and development. Washington DC: Island Press, 1997:3-115.

2 Kellert SR, Wilson EO. The biophilia hypothesis. Washington DC: Island Press, 1993:180. Fromm E. The anatomy of human destructiveness. New York: Holt, Rinehart \& Winston: 366 .

4 Lorenz K. Die acht Todsünden der zivilisierten Menschheit. Munich: Piper, 1973:15-142.

5 Gelder M, Mayou R, Cowen P, eds. Oxford textbook of psychiatry. Oxford University Press, 1996:211-7.

6 Sundquist K, Frank G, Sundquist J. Urbanisation and incidence of psychosis and depression. Follow-up study of 4.4 million women and men in Sweden. BrJ Psychiatry 2004;184:293-8

7 Peen J, Dekker J. Urbanisation as a risk indicator for psychiatric admission. Soc Psych Psych Epidemiol 2003;38:535-8.

8 Ulrich RS, Simons RF, Losito BD, Fiorito E, Miles MA, Zelson M. Stress recovery during exposure to normal and urban environments. J Environ Psychol 1991;11:201-230.

9 Katcher A, Beck A. New perspective on our lives with companion animals. Pennsylvania, USA: University of Pennsylvania Press, 1983:407-83.

10 Hartig T, Mang M, Evans GW. Restorative effects of natural environment experiences. Environ Behav 1991;23:3-26.

11 Cooper JE. Pets in hospitals. BMJ 1976;1:698-700.

12 Rice S, Brown L, Caldwell HS. Animals and psychotherapy: a survey. J Community Rice S, Brown L, Cal 1973;1:323-6.
Psce J. 16we

13 Price J. The dominance hierarchy and the evolution of mental illness. Lancet; $1967 ;$;i:243-6.

14 Price J, Sloman L, Gardner R Jr, Gilbert P, Rohde P. The social competition hypothesis of depression. BrJ Psychiatry 1994;164:309-15.

15 Dawson A, Tylee A. Depression: social and economic time bomb. London: BMJ Publishing Group, 2001:3-48.

16 Nesse RM. Evolutionary explanations of emotions. Hum Nature 1996;1:261-89.

17 World Health Organization. The ICD-10 classification of mental and behavioural disorders: diagnostic criteria for research. Geneva, Switzerland: WHO, 1993.

18 Hamilton M. Development of a rating scale for primary depressive illness. Br J Soc Clin Psychol 1976;6:278-96.

19 Zung WWK A rating instrument for anxiety disorders. Psychosomatics 1971;12:371-9.

19 Zung WWK. A rating instrument for anxiety disorders. Psychosomatics 1971;12:371-9.

21 Beck AT, Ward CH, Mendelson M, Erbaugh J. An inventory of measuring depression. Arch Gen Psychiatry 1961;4:53-63.

22 American Psychiatric Association. Handbook of psychiatric measures. Am J Psychiatry 2000;515-89.

23 Blehar MC, Rosenthal NE. Seasonal affective disorders and phototherapy: report of the National Institute of Mental Health-sponsored workshop. Arch Gen Psychiatry 1989;46:469-74.

24 Levine B. Use of hydrotherapy in reduction of anxiety. Psychol Rep 1984;55:526. (Accepted 27 June 2005)

bmj.com 2005;331:1231

Department of Health Sciences, Division of Clinical Psychiatry, University of Leicester Medical School, Leicester General Hospital, Leicester LE5 4PW

Christian Antonioli PhD candidate in psychiatry

Michael A Reveley professor of psychiatry

Correspondence to: M A Reveley rev@le.ac.uk 